\title{
Statistics Oversight Documentation
}

National Cancer Institute

\section{Source}

National Cancer Institute. Statistics Oversight Documentation. NCI Thesaurus. Code C115733.

Records detailing the process of monitoring and/or supervising the interpretation of statistical data generated from a clinical trial. 